\title{
Crisis Management and Strategy Analysis of Rural Credit Cooperatives
}

\author{
Haipeng Zhu \\ Nanfang College, Sun Yat-sen University, Guangzhou Guangdong, 510970, China
}

Keywords: rural credit cooperatives; crisis management; strategy

\begin{abstract}
As an important small and medium-sized financial institution in the development process in China, rural credit cooperatives are undergoing profound changes in the operating environment, development model, and business risks due to the impact of financial reforms in the current development process, and due to the influence of many unfavorable factors. As a result, the risks to the crisis faced by rural credit cooperatives have increased.
\end{abstract}

Therefore, starting from the characteristics of rural credit cooperatives and the necessity of crisis management, this paper discusses the ways in which rural credit cooperatives conduct crisis management, and in this way helps China's rural credit cooperatives to improve their self-management in developing, thus, to promote the healthy development of rural credit cooperatives in the future.

\section{Introduction}

As an important part of China's banking financial institutions, rural credit cooperatives are rural cooperative financial institutions established with the approval of the People's Bank of China, consisting of members in stocks, democratic management, and financial services for members. In the current development process, the rural credit cooperatives mainly develop in the form of cooperation. The cooperative institutions will raise personal funds to achieve mutual help and assistance, and ultimately enable their deposit and loan business and loan business activities to be effectively carried out. Rural credit cooperatives have extremely close economic links with rural areas and farmers during the development process. The reason why the country needs to do a good job in the construction of rural credit cooperatives is mainly because the agricultural production work carried out by farmers will lead to different needs of farmers for funding because of the different seasons, which will lead to the number and scale of loans for the country. It has also been greatly affected, and it is very easy for farmers to be constrained by financial factors during the development process. So that, in order to ensure that farmers can smoothly obtain corresponding loans to carry out agricultural activities in the course of carrying out work, the country needs to establish rural credit cooperatives in this process to provide more help for the development of farmers' agricultural economy.

\section{The Characteristics of Rural Credit Cooperatives}

Rural credit cooperatives, as an important banking financial institution formed in the development process in China, are mainly funded by farmers and other rural individuals in the process of their establishment. They also need rural credit in the course of business operations. The members of the club choose suitable personnel to manage the rural credit cooperatives through democratic elections, and they also have to accept the supervision of the members during the process to ensure that relevant personnel have higher work in the process of working in rural credit cooperatives. effectiveness. At the same time, financial institutions need to have sufficient funds to ensure the smooth development of their work. Among them, the share capital, retained reserves, and absorbed deposits paid by cooperative members are used as the source of funds for rural credit cooperatives, and they are used as rural credit cooperatives. The main source of funds for the society is to ensure that members can give more help to the members in time when there are 
financial problems, and to carry out corresponding work through the distribution of short-term production and living loans and consumer loans. ${ }^{[1-2]}$ Meanwhile, with the continuous improvement of the economic level of rural credit cooperatives in the course of development, rural credit cooperatives have gradually broadened their lending channels when they provide financial needs for their members, and since rural credit cooperatives are in the process of their current development, business procedures are relatively simple. Because of its flexibility, it is highly valued by the members of the rural credit cooperatives.

\section{The Necessities of Crisis Management in Rural Credit Cooperatives}

Although the rural credit cooperatives currently are developing in significant level, rural credit cooperatives, as a local financial institution for small and medium-sized financial enterprises under a multi-level legal person system, have great differences from state-owned banks, resulting in rural credit cooperatives. In the current development process, the agency has gradually developed a crisis of development. For this reason, in the current development process, rural credit cooperatives need to actively take effective measures to manage the crisis, and it is also a very necessary job.

Facing to unexpected crises, it can easily to result in serious imbalances in the value orientation of interest between rural credit cooperatives and public relations. If this crisis can not be resolved in a reasonable and effective manner, it will create a series of contradictions and disputes between the rural credit cooperatives and the public in the exchange of interests, and even the embarrassing situation of being enemies with the public, which seriously impact on the development of the operation of rural credit cooperatives. Consequently, if the rural credit cooperative manages the crisis in the course of carrying out its work, it can help the rural credit cooperatives turn the crisis into a turning point for the rural credit cooperatives and find an important opportunity to promote the smooth development of rural credit cooperatives again. Not only is it beneficial to reestablishing a competitive reputation for rural credit cooperatives, but it can also provide more assistances for the establishment of a healthy image for rural credit cooperatives and the effectively handling of crisis management in rural credit cooperatives. ${ }^{[3]}$

Positive public relations can effectively help rural credit cooperatives to form their image, establish brands, expand markets, and establish positive interpersonal relationships. It is also of great help to strengthen the cohesion and appeal of rural credit cooperatives. ${ }^{[4]}$ Therefore, in the current development process, in order to ensure its survival and development in the process of development, rural credit cooperatives can quickly gain the opportunity to communicate with consumers and gain their trust and recognition, and help rural credit cooperatives build up positive image to ensure that rural credit cooperatives get rid of difficulties in the process of continuous development. Thence, as the rural credit cooperatives can do a good job in crisis management in developing, which will be able to help rural credit cooperatives to establish a positive and healthy image. This will greatly promote the normal development of rural credit cooperatives.

With the continuous development of China's Internet technology, social information has spread faster, and it has also gained more advantages in the scope and channels of communication. However, in the process of disseminating information, the new media not only produce more positive information, but also a large amount of negative information, which in turn makes the rural credit cooperatives seriously affected by negative information in development. Therefore, in order to prevent the rural credit cooperatives from being severely affected during the development of the new media era, the rural credit cooperatives need to establish the internal control of crisis management in this process, and then help the rural credit cooperatives to actively participate in crisis management. By this program, it is helpful for rural credit cooperatives to fully master all causes of the crisis, characteristics, and laws, and then respond to all possible crises, and be able to quickly and effectively deal with all aspects of the relationship, and thus further help rural credit cooperatives reduce losses. 


\section{The Methods of Crisis Management in Rural Credit Cooperatives}

Due to the influence of many factors, it is easy to tragger the crisis in the development of rural credit cooperatives, which will cause serious losses. Therefore, in order to carry out a reasonable and effective solution to this problem and ensure that managers can avoid crises in the management of rural credit cooperatives, it is necessary to work effectively in the establishment and improvement of crisis management system. For example, at the beginning of a crisis, the rural credit cooperatives can manage the crisis in a timely manner and control it within a reasonable range to solve the problem, so as to achieve the target as "major issues to minor ones out" ${ }^{5]}$. Thence, in order to achieve this ideal requirement, it is necessary to establish a crisis early warning mechanism and establish a crisis response and disposal mechanism, which will greatly assist the development of the routines of rural credit cooperatives.

If rural credit cooperatives cannot effectively prevent the emergence and development of crises in their work, it is necessary to take the right way to deal with related issues. Among these, in the process of actively responding to the crisis, the rural credit cooperatives must not evade the contradiction by attempting to cover up the crisis. This can only further magnify the contradictions that have arisen, and at the same time, we need to communicate with the other party in a sincere and sincere manner during the crisis process without shirking responsibilities and adopt relatively rapid measures to achieve the isolation of the crisis. This will help resolve related issues to a certain extent ${ }^{[6]}$. Moreover, in the best handling time, we must strive to complete the crisis, otherwise, the price paid by the crisis will be higher, the negative impact will be even greater, and the human, material resources and energy will be cost more.

In the process of responding to the crisis, rural credit cooperatives also need to conduct training in crisis management according to different personnel. In rural credit cooperatives, not only management work for employees needs is necessary, but also middle-level management personnel and senior managers are actively should be involved in crisis response training. By training, awareness of crisis among all employees is improved, and abilities of crisis recognition, prevention, and handling are enhanced. That is helpful for rural credit cooperatives to take proper actions facing to crisis. In crisis management training, it is possible to do training in crisis psychological quality training, relevant departments' coordination, emergency actions taking, and crisis management advocacy. By training managers, relevant issues can be resolved, which can promote the continuous improvement of the ability of rural credit cooperatives to handle the crisis.

\section{Conclusion}

In summary, the rural credit cooperatives will often be affected by crisis factors in their routine. Therefore, if we do not take effective measures, we will not only tragger serious damage to the future development of rural credit cooperatives. Meanwhile, we should also do well in crisis management training for managers. Consequently, it is possible to effectively control the crisis situation of rural credit cooperatives and promote the establishment of a positive image in the process of continuous development. It is necessary to establish and improve crisis management system mechanisms in the process of helping rural credit cooperatives to cope with the crisis. To carry out work on crisis management communication, but also to do a good job in crisis management training for managers. In this way, for promoting rural credit cooperatives routine is conducive to the sustained development of China's financial industry.

\section{References}

[1] Liu Chunlong. Discussion on Problems and Countermeasures in Credit Risk Management of Rural Credit Cooperatives [J]. Business Manager, 2014,10(14):22.

[2] Wei Shangchao. Credit Management and Risk Prevention of Rural Credit Cooperatives [J]. Modern Economic Information, 2014, 2(1):281-281. 
[3] Sheng Yi. Problems and Countermeasures in Credit Management of Rural Credit Cooperatives [J]. New Finance (Theory), 2014, 2(1):48-50.

[4] An Yuwen. Analysis of Crisis Management and Strategies of Rural Credit Cooperatives [J]. Times Finance, 2016, 3(6): 142-143.

[5] Shang Guangfeng. On the Current Situation and Countermeasures of the Management of Loan Projects in Rural Credit Cooperatives in China [J]. New Business Weekly, 2017, 3(4):30.

[6] Rong Jianzhi. Problems and Strategies in Credit Management of Rural Credit Cooperatives [J]. Northern Economic and Trade, 2016, 4(5):111-112. 